\title{
Polymeric Materials for Membrane Contactor Devices Applied to Water Treatment by Ozonation
}

\author{
Felipe Rodrigues Alves dos Santos ${ }^{a *}$, Cristiano Piacsek Borges ${ }^{a}$, Fabiana Valéria da Fonseca ${ }^{b}$
}

\author{
${ }^{a}$ Programa de Engenharia Química - COPPE, Universidade Federal do Rio de Janeiro - UFRJ, \\ Av. Horácio Macedo, 2030, Cidade Universitária, CP 68502, CEP 21941-972, Rio de Janeiro, RJ, Brazil \\ ${ }^{b}$ Escola de Química, Universidade Federal do Rio de Janeiro - UFRJ, Av. Athos da Silveira Ramos, \\ 149, Cidade Universitária, CEP 21941-611, Rio de Janeiro, RJ, Brazil
}

Received: June 21, 2015; Revised: August 11, 2015

\begin{abstract}
In water treatment process ozone is applied to disinfection and to remove organic pollutants. Membrane contactor devices are used as a physical barrier to separate two fluids without phase dispersion and it can be used to improve the ozonation efficiency. Polymeric materials are used in membrane contactors and they can react with ozone, suffering degradation and losing its mechanical properties. In this work, commercial polymeric membranes were selected to investigate their interaction with ozone in gaseous phase. It was evaluated changes in polymer structures and in membrane morphology by FTIR, DSC, TGA and SEM. It was observed preferential ozone attack to double carbon-carbon bonds in the main polymer chain for polyimide and polysulphone membranes. Polypropylene has single carbon-carbon bonds and its reaction with ozone was less intensive. For polydimethylsiloxane membranes the ozone attack seems to occur in the carbon-silicon bond, leading to loss of mechanical and thermal properties.
\end{abstract}

Keywords: ozone, membrane contactor, polymer degradation, water treatment

\section{Introduction}

Ozone is a gas of triatomic oxygen molecule with great oxidative power, characteristic odor and colorless, and it can react with a number of organic compounds. In water treatment process it has been frequently used to disinfection and to destroy contaminants. The oxidation reaction can occur by either or both modes in aqueous solution: direct oxidation by molecular ozone and oxidation by hydroxyl free radicals produced during the decomposition of ozone ${ }^{1-4}$. Ozone is an unstable molecule and it is generated in situ by electrical discharges, converting part of gaseous oxygen from dry air or liquid oxygen 5 .

Although many authors proposed a variety of ozonolysis mechanism in the last century ${ }^{6}$, the ozonolysis mechanism proposed by Criegee ${ }^{7-10}$ is the one currently used, where polymers with double carbon-carbon bonds in the main chain can easily react with ozone. In this mechanism, an ozone molecule attacks a double bond of carbons in a dipolar cycloaddition process forming an unstable primary ozonide (molozonide). The molozinide cleaves the bond to form a carbonyl oxide (zwitterions) and a carbonyl compound. However, both generated molecules can be recombined creating a secondary ozonide, a trioxolane ring ${ }^{11,12}$. This last step leads to cross-linking or decomposition of the polymeric materials.

Cataldo $^{12}$ investigation indicated that polymers composed by molecules with single bonds in their structure exhibit good resistance against ozone attack. Nevertheless, some authors proposed a simple mechanism of initiation and propagation for ozone attack of single bonds structures where various

*e-mail: felipe@peq.coppe.ufrj.br groups, as carboxyl, ketone, etc., are created with elevated ozone concentrations ${ }^{13-15}$.

Goto et al. ${ }^{16}$ evaluated the chemical reactivity between ozone and different polymers through material thickness reduction. The authors confirmed a faster structural change in polymers with carbon-carbon double bond in main chain than polymer with carbon-carbon double bond in the side chain. According to the authors, polymeric structures without carbon-carbon double bond did not exhibit significant changes by ozone attack.

Ouyang et al. ${ }^{17}$ studied the effect of ozone on siloxane polymers and verified the formation of a silicon oxide film at the surface of the material. They observed shifts in the binding energies of siloxane groups to values very close to the binding energy of silicon oxide. Furthermore, they observed that there action rate is a function of the siloxane group and the superficial film has limited thickness (e.g., 20 to $30 \mathrm{~nm}$ for polydimethylsiloxane).

Ozone is also used to change the surface properties of polymers ${ }^{18-22}$. MacManus et al. ${ }^{20}$ studied surface modification of polypropylene through ozone and UV exposition, observing improvement in hydrophilicity. According to the authors, the presence of water vapor accelerates the oxidation process.

Usually, in water treatment process ozone is dispersed into aqueous phase with mass transfer limitations, leading to high energetic costs. Membrane contactors have been pointed out as a good alternative for gas transfer to the liquid phase. These devices enable a defined interfacial area and promote non-dispersive mass transfer, reducing gas losses. Advantages of membrane contactors are a high area/volume 
ratio and energetic efficiency, as well as it is modular and can be easilyscale-up ${ }^{23-25}$.

Unlike most membrane processes, membrane contactors have no selectivity to the separation. The main purpose of these devices is to keep the involved phases separated, operating as an inert medium, which allows gas and liquid phases contact without dispersion ${ }^{26-29}$.

This work investigated the ozone resistance of polydimethylsiloxane, polypropylene, polytetrafluoroethylene, polyvinylidenefluoride, polyetherimide and polyethersulfone. These polymers are frequently used in membrane contactors.

\section{Experimental}

\subsection{Polymeric membranes and ozone generation}

Table 1 presents different commercial polymeric membranes selected to verify the ozone attack. Sample of these membranes were prepared with surface area of 158 to $2450 \mathrm{~mm}^{2}$ (depending of the membrane) and kept in a glass recipient where they were subjected to ozone gas for 2 and 4 hours at $5.25 \mathrm{~g} . \mathrm{h}^{-1}$ at room temperature. The ozone stream was generated from pure oxygen by an ozone generator (UTK-O-8, Unitek), and the ozone concentration in the gas phase was continuously measured by an ozone analyzer (H1, In USA).

\subsection{Scanning Electron Microscopy (SEM)}

In order to verify changes on membrane morphology after exposure to ozone, samples were observed by scanning electron microscope (QUANTA 200, FEI Co.). All samples were dried in vacuum at room temperature for $24 \mathrm{~h}$, frozen in liquid nitrogen and then broken in middle. The surface and cross section of the sample were then coated with a thin layer of gold by sputtering.

\subsection{Thermal analysis}

Thermogravimetric analysis (TGA, Pyris 1, Perkin Elmer) and Differential Scanning Calorimetry (DSC, DSC-7, Perkin Elmer) were performed under nitrogen atmosphere. For TGA and DSC samples with weight in 5 to $10 \mathrm{mg}$ range were heated at $10{ }^{\circ} \mathrm{C} \cdot \mathrm{min}^{-1}$, in the temperature range of 30 to $800{ }^{\circ} \mathrm{C}$ and -20 to $400^{\circ} \mathrm{C}$, respectively. The DSC was previously calibrated with $\mathrm{In}$ and $\mathrm{Zn}$ standards and the melting temperature $\left(T_{M}\right)$ data were measure in the second melting.

\subsection{Infrared spectroscopy}

Samples of the membranes were analyzed before and after ozone exposition by fourier transform infrared spectroscopy (FTIR, Spectrum 100, Perkin Elmer) with attenuated total reflectance (ATR). The IR spectra were collected in the range 4000 to $650 \mathrm{~cm}^{-1}$ with $4 \mathrm{~cm}^{-1}$ of resolution.

\section{Results and Discussion}

SEM, TGA, DSC, and FTIR analysis were used to characterize the samples and identify modifications that would be occurred by the oxidation process of the polymeric membranes, helping in the elucidation of ozone attack.

\subsection{Morphological changes of membrane}

Figure 1 shows photomicrographs of the membranes cross sections before exposition to ozone. One may note that polypropylene (PP) hollow fiber has a very thin wall thickness and small pores (Figure 1a), while polyethersulfone (PES) and polyetherimide (PEI) hollow fibers exhibit large

Table 1. Commercial membranes selected for ozone oxidation experiments.

\begin{tabular}{|c|c|c|c|c|}
\hline Polymer & Structures & $\begin{array}{c}\text { Porosity of } \\
\text { membrane (\%) }\end{array}$ & Geometry & Supplier \\
\hline Polyetherimide (PEI) & & 75 & Hollow fiber & $\begin{array}{l}\text { PAM Membranas } \\
\text { Seletivas Ltda. }\end{array}$ \\
\hline Polyethersulfone (PES) & & 65 & Hollow fiber & Praxair Co. \\
\hline Polypropylene (PP) & & 30 & Hollow fiber & Minntech Co. \\
\hline $\begin{array}{l}\text { Polytetrafluoro ethylene } \\
\text { (PTFE) }\end{array}$ & & 85 & Flat sheet & Millipore Ltda. \\
\hline $\begin{array}{l}\text { Polyvinylidene fluoride } \\
\text { (PVDF) }\end{array}$ & & 70 & Flat sheet & Millipore Ltda. \\
\hline Polydimethylsiloxane & & 0 & Hollow fiber & Medicone Ltda. \\
\hline
\end{tabular}


macrovoids in their cross sections (Figure 1c and Figure 1d, respectively). Polydimethylsiloxane (PDMS) hollow fiber has no visible pores, characterizing dense membrane morphology (Figure 1b). The cross sections of polyvinylidenefluoride (PVDF) and polytetrafluoroethylene (PTFE) membranes show typical sponge like morphology with interconnected pores (Figure 1e and Figure 1f).

After contact with ozone the membrane materials investigated present different behavior. PES and PEI membranes were severely attacked by ozone, losing completely their

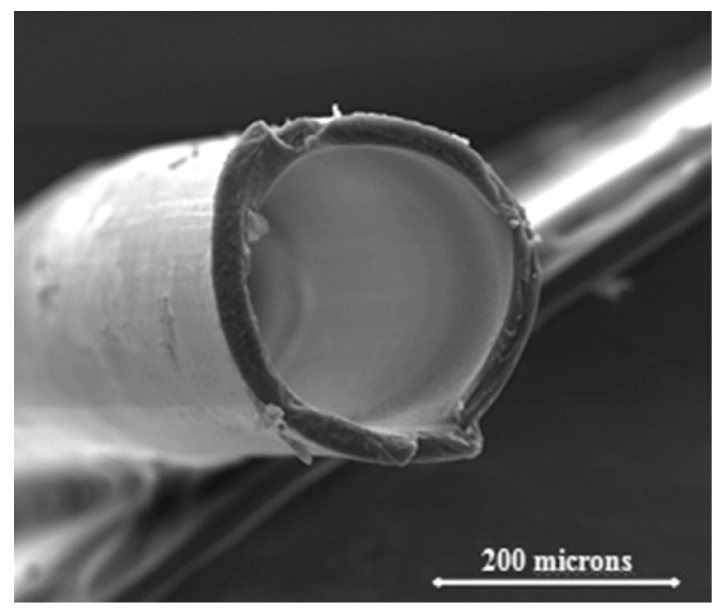

(a)

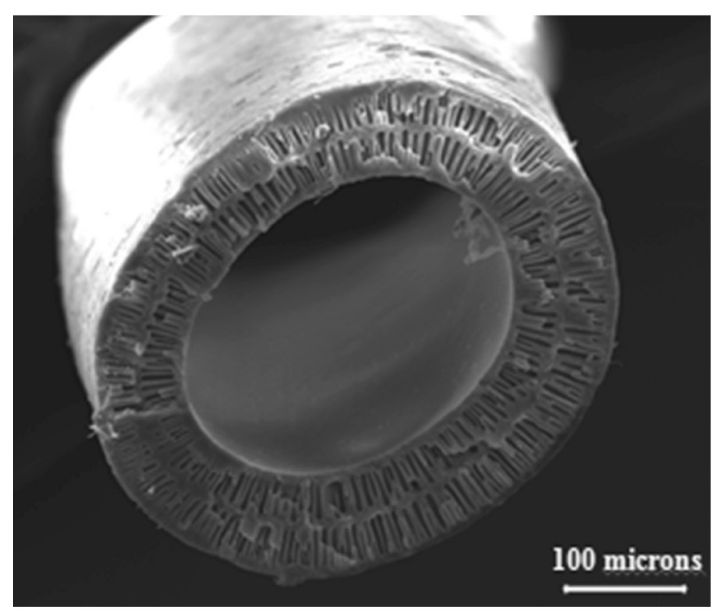

(c)

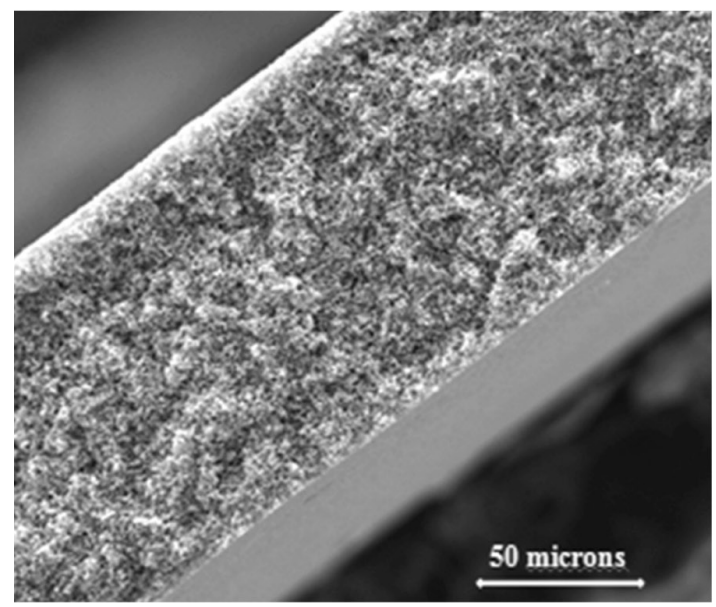

(e)

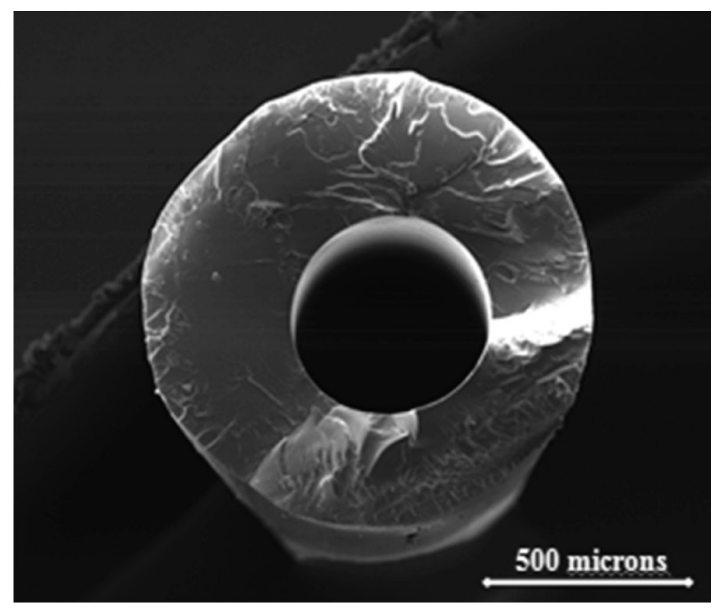

(b)

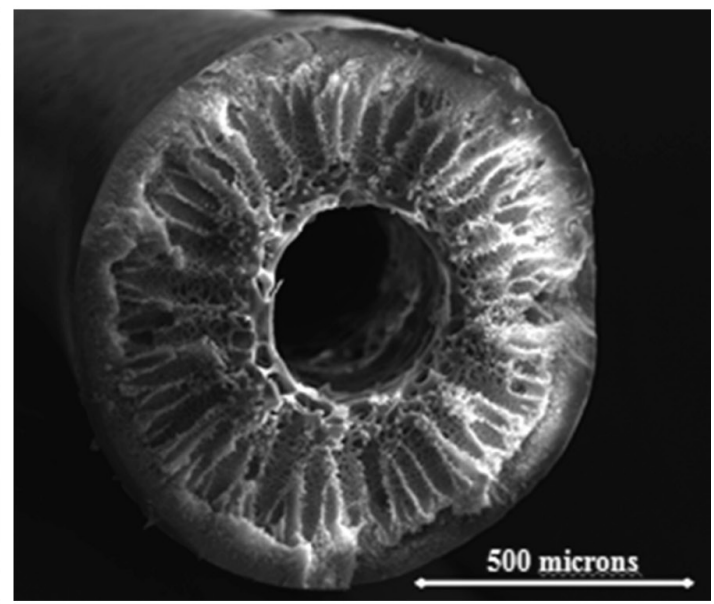

(d)

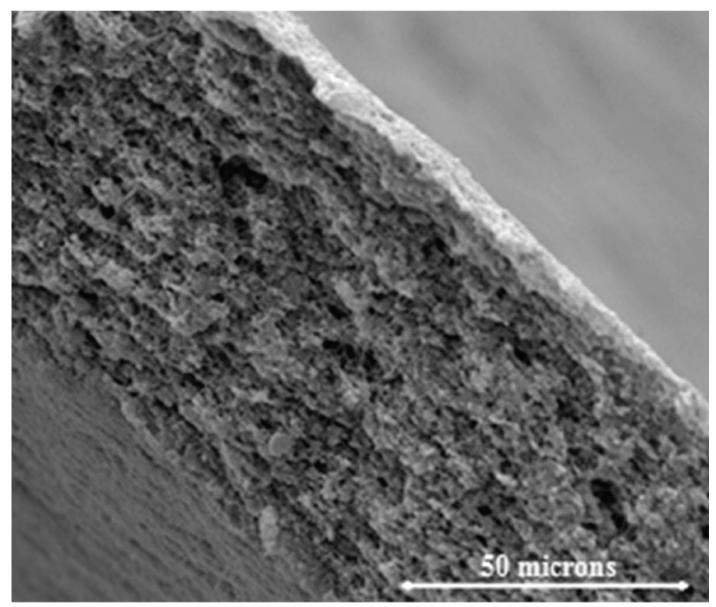

(f)

Figure 1. SEM photomicrographs of the cross section of polymeric membranes before the contact with ozone. (a) PP; (b) PDMS; (c) PES; (d) PEI; (e) PVDF and (f) PTFE. 
mechanical properties as illustrated in the photographs (a) and (b) of Figure 2, respectively. Probably, it is consequence of the presence of double carbon-carbon bonds in the polymer main chain in aromatic rings. PP membrane also presented mechanical loss (Figure 2c), but only after 4 hours of contact with ozone, which indicates higher resistance to ozone oxidation than PEI and PES. It was not observed any macroscopic changes for the others membranes, i.e., PDMS, PVDF and PTFE.

SEM analyses were performed with PP, PDMS, PTFE and PVDF membranes samples to observe any morphological changes and Figure 3 shows the photomicrographs. PEI and PES membranes were fully degraded after ozone contact, making unnecessary the SEM analysis.

PP membranes were affected by ozone oxidation as discussed and Figure 3a shows its external surface in two different magnitudes. In low magnification one may observe a longitudinal fracture in the fiber, indicating polymer degradation. At high magnification it is observed typical pores of PP membranes, however the pore diameter is somewhat larger than in the original membrane (data not shown). Larger pores may increase the ozone mass transfer to the liquid phase, but also may cause loss of mechanical resistance. It is important to stress that the conditions of ozone exposition was much severe than in a real operation of a membrane contactor and PP membrane could be considered to use in mild conditions.

Figures $3 b, 3 c$ and $3 d$ show the cross sections of PDMS, PTFE and PVDF membranes, respectively. There was no modification observed by SEM photomicrographs for theses membranes, indication higher resistance to ozone oxidation then the other investigated polymers.

\subsection{Thermal properties of polymers}

Analyses of TGA and DSC were carried out to verify molecular modifications in the polymeric structures. Degradation and melting temperatures were verified before and after contact with ozone to observe the thermal stability of the selected polymeric membrane materials. Before ozone exposition, Table 2 shows that PP, PVDF and PTFE samples present similar melting temperature $\left(T_{M}\right)$ to those reported in literature ${ }^{30}$. After contact with ozone only PP membrane presented a reduction in $T_{M}$, which may be related to degradation of the polymeric chain. PEI and PES materials was not submitted to thermal analyzes due to intense fibers deterioration in a few minutes of contact test.

Table 2. Melting temperature of membrane samples before and after ozone exposition.

\begin{tabular}{cccc}
\hline \multirow{2}{*}{ Polymer } & \multicolumn{3}{c}{$\boldsymbol{T}_{\boldsymbol{M}}\left({ }^{\circ} \mathbf{C}\right)$} \\
\cline { 2 - 4 } & No contact & $\begin{array}{c}\text { 2 hours of } \\
\text { contact }\end{array}$ & $\begin{array}{c}\text { 4 hours of } \\
\text { contact }\end{array}$ \\
\hline PP & 162.2 & 159.2 & 152.4 \\
PTFE & 326.7 & 326.9 & 327.2 \\
PVDF & 159.5 & 159.5 & 159.5 \\
\hline
\end{tabular}

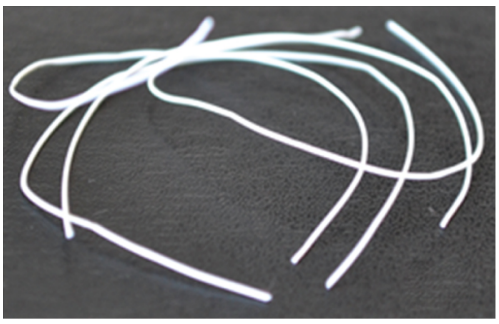

(a1)

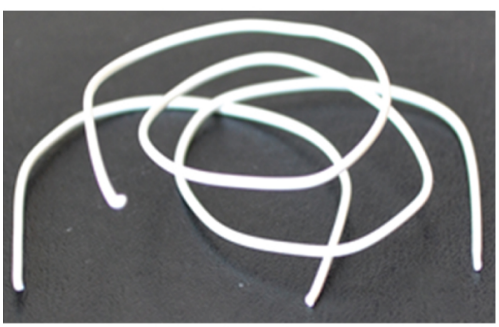

(b1)

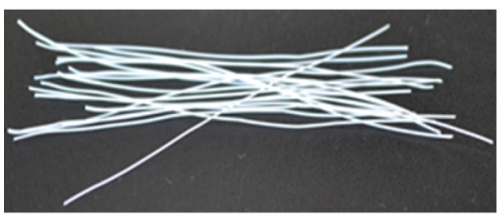

(c1)

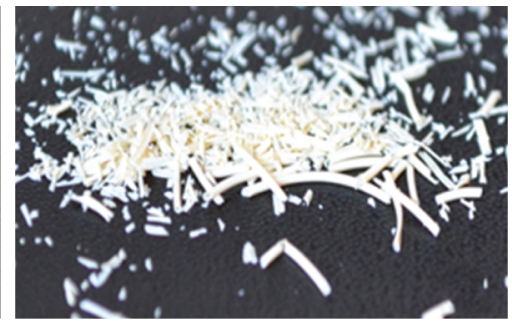

(a2)

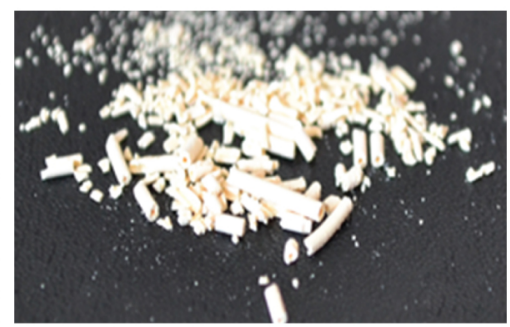

(b2)

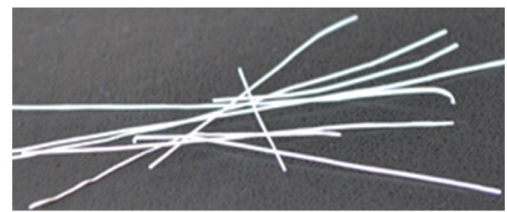

(c2)

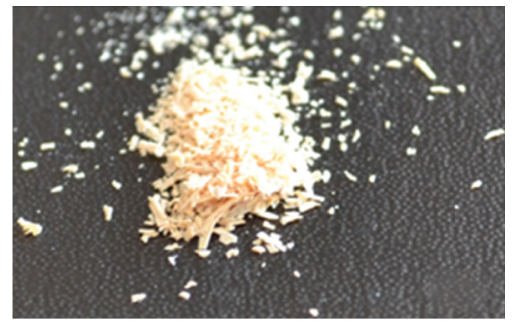

(a3)

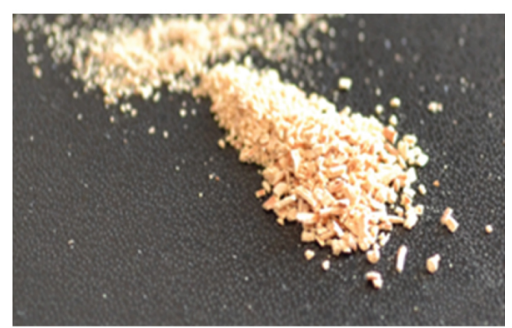

(b3)

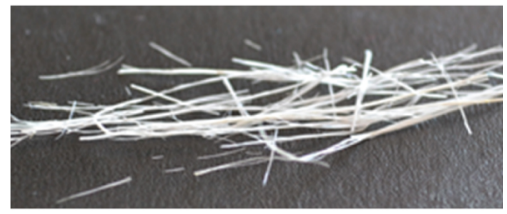

(c3)

Figure 2. Photographs of polymeric membranes before the contact with ozone: (a1) PES, (b1) PEI and (c1) PP; after 2h of ozone exposition: (a2) PES, (b2) PEI and (c2) PP; and after 4hof ozone exposition: (a3) PES, (b3) PEI and (c3) PP. 
Figure 4 shows the derivative mass loss of PP, PDMS, PVDF and PTFE samples with increase in the temperature. The peak represents the temperature range where the polymer degraded. A polymer is thermally stable until it reaches its

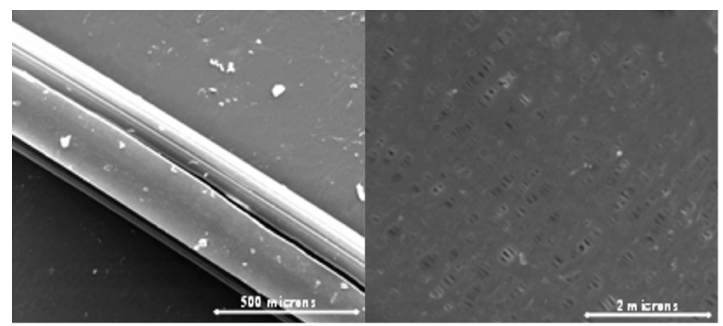

(a)

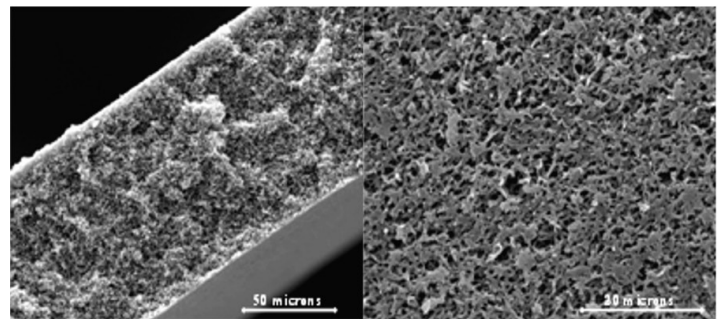

(c) own characteristic decomposition temperature. Decomposition process occurs in two ways, as chain depolymerization or random decomposition ${ }^{31}$. In the first process there is the release of monomer unit from chain end or at a weak link.

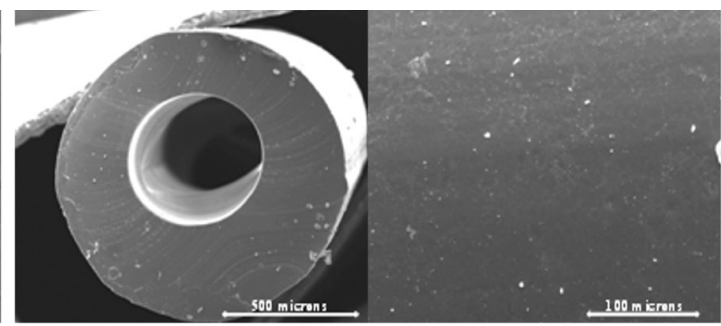

(b)

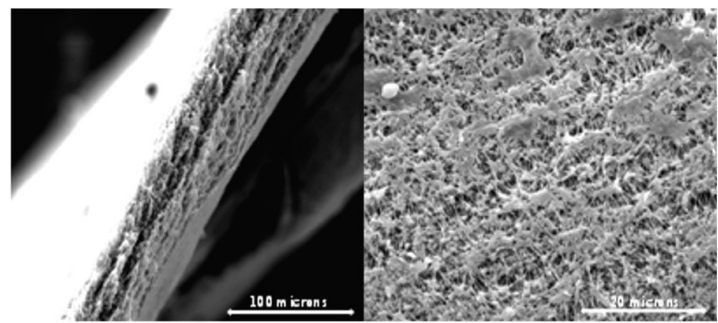

(d)

Figure 3. SEM photomicrographs of polymeric membranes after 4h of ozone exposition. (a) PP; (b) PDMS; (c) PVDF and (d) PTFE.

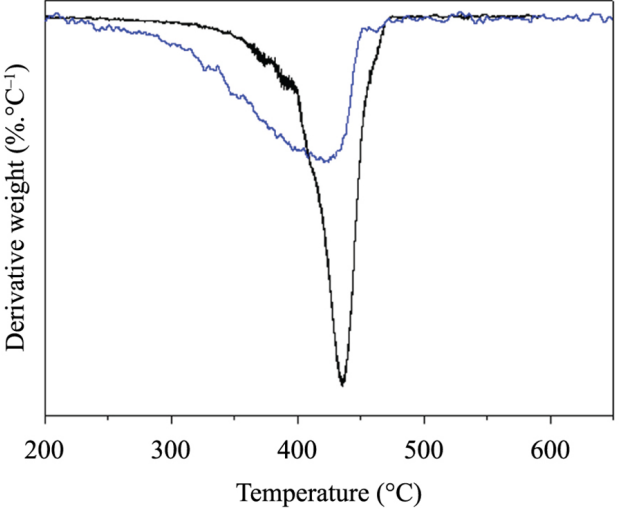

(a)

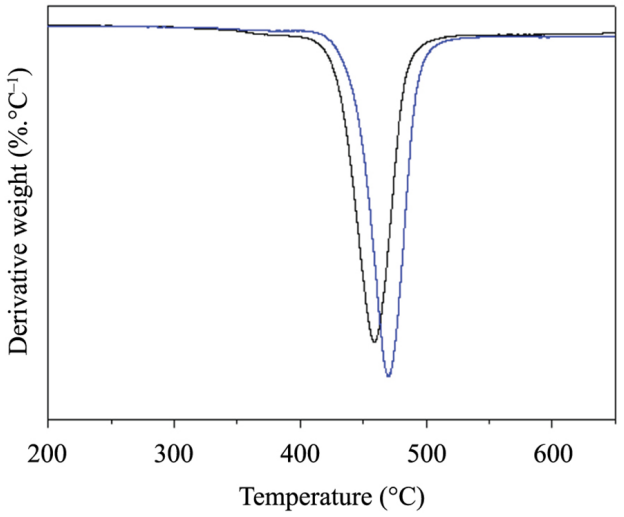

(c)

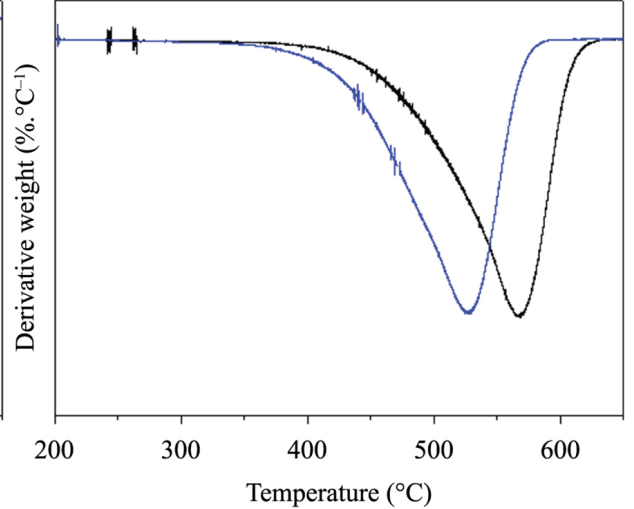

(b)

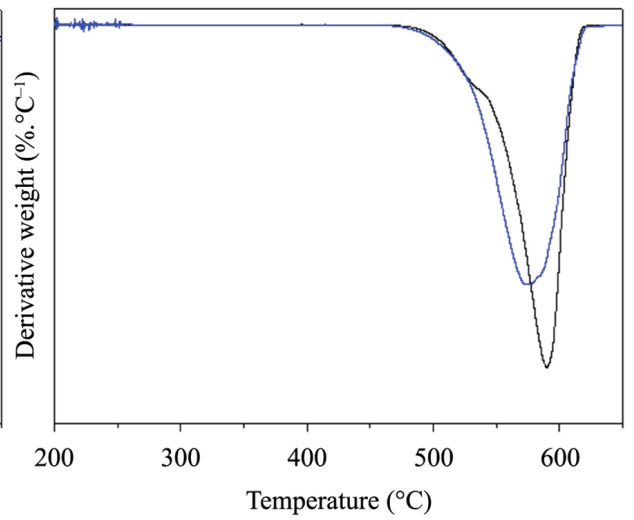

(d)

Figure 4. DTG analysis of (a) PP; (b) PDMS; (c) PVDF and (d) PTFE. Black line is relative to sample without contact with ozone and blue line to the sample after $4 \mathrm{~h}$ of ozonation. 
In the other one, there are chain ruptures at random locations, giving a disperse mixture of fragments. Both processes cause mass losses and, consequently, weight reduction at certain temperature. The reduction of degradation temperatures could mean changes in flexibility of polymer and lower thermal resistance.

In Figure 4a one may notice that PP presents a considerable reduction of thermal stability after 4 hours of contact with ozone characterized by a significant reduction in the initial degradation temperature. This result confirms the previous morphological analysis.

As shown in Figure 4b, PDMS membrane showed a small shift in the temperature range where degradation occurs. Ouyang et al. ${ }^{17}$ reported that siloxane polymer are modified after ozone/UV exposition, which was related to removal of organic carbon and formation of silicon dioxide. Hence, change in degradation temperature could be a consequence of reduction in polymer molecular weight.

It was not observed significant modifications of the degradation temperatures range of PVDF and PTFE samples,

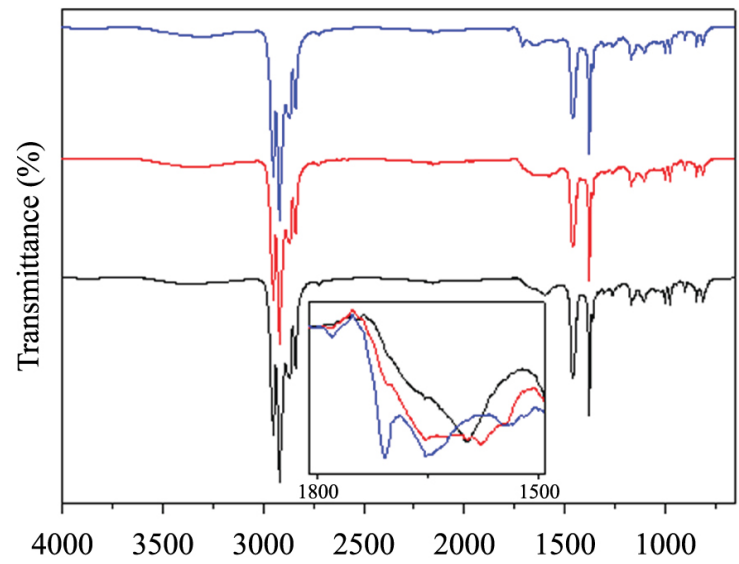

Wavenumber $\left(\mathrm{cm}^{-1}\right)$

(a)

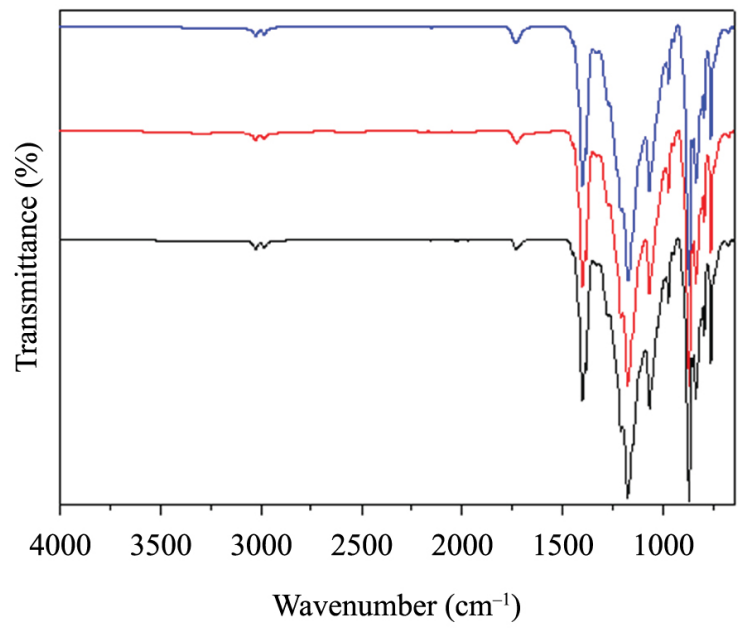

(c)
Figures $4 \mathrm{c}$ and $4 \mathrm{~d}$, respectively. It indicates that the ozone contact does not affect the thermal stability of these materials.

\subsection{Infrared analysis of the polymers}

FTIR spectra were obtained to investigate the qualitative effect of ozone exposition on the polymeric membranes. Figure 5 shows FTIR spectra of PP, PVDF, PDMS and PTFE membranes before ozone contact and after 2 and 4 hours of exposition.

The FTIR spectra of PP membrane is portrayed in Figure 5a and it is possible to observe changes in carboxyl $(\mathrm{C}=\mathrm{O})$ and alkyl $(\mathrm{C}-\mathrm{H})$ bands, which may be related to reaction with ozone. Appearance of a band in $1708 \mathrm{~cm}^{-1}$, region of ketone carboxyl groups $(\mathrm{C}=\mathrm{O})$, also reflects changes occurring in the polymer structure. Although Cataldo ${ }^{12}$ had observed that materials with single bonds showed great resistance to ozone attack, in the present work two polymeric materials, PP and PDMS, have suffered break of the single bonds due to ozone attack at high concentrations used, as observed in the literature $\mathrm{e}^{13-15}$.

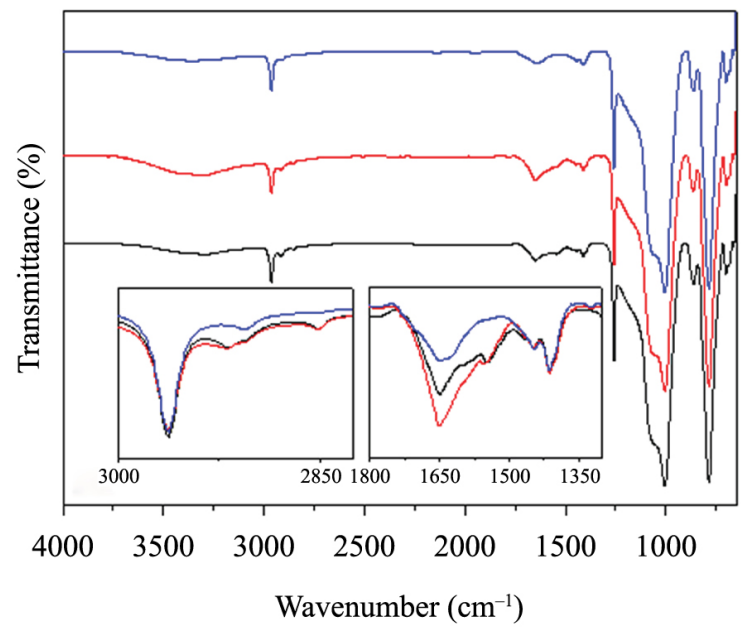

(b)

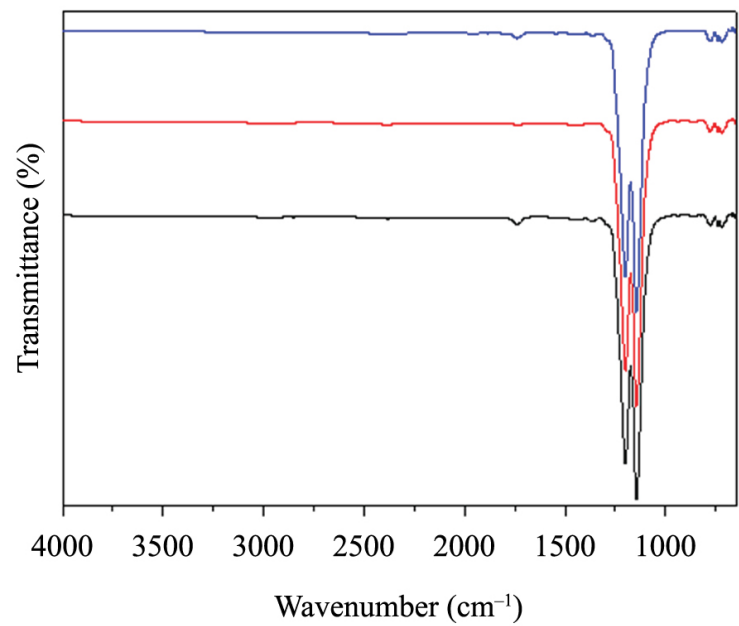

(d)

Figure 5. FTIR spectra of selected membranes. (a) PP; (b) PDMS; (c) PVDF and (d) PTFE. Black line is relative to sample without contact with ozone, red and blue lines to the sample after $2 \mathrm{~h}$ and $4 \mathrm{~h}$ of ozonation, respectively. 
Similar modifications were also observed for PDMS membranes (Figure 5b), moreover for prolonged exposition to ozone it was observed changes in the spectral region $2990-2855 \mathrm{~cm}^{-1}$ and $1485-1415 \mathrm{~cm}^{-1}$ of alkyl groups $\left(-\mathrm{CH}_{3}\right)$ from long chain with stretching vibration (symmetric and asymmetric) and asymmetric bending vibration, respectively ${ }^{32}$. After two hours of ozone exposition an increase in the band at $1645 \mathrm{~cm}^{-1}$ relative to double bonds is also observed in Figure 5b. It is probably related to carboxyl groups formed by ozonation of alkyl groups of the PDMS. However, after four hours of ozone exposition is it observed a reduction of this band, meaning a removal of $\mathrm{C}=\mathrm{O}$ bonds to form silicon oxide as described in literature ${ }^{14}$. It is import to accentuate that no modifications were observed in bands relative to the $\mathrm{Si}-\mathrm{O}-\mathrm{Si}\left(865 \mathrm{~cm}^{-1}\right)$ or to $-\mathrm{CH}_{3}$ in the bond $\mathrm{Si}-\mathrm{CH}_{3}\left(785 \mathrm{~cm}^{-1}\right)$.

Figures $5 \mathrm{c}$ and $5 \mathrm{~d}$ show spectra of PTFE and PVDF membranes, respectively, and no modifications were observed even after 4 hours of ozone exposition, confirming their resistance to ozone oxidation and as appropriated material for membrane contactors.

\section{References}

1. Staehelin J and Hoigné J. Decomposition of ozone in water in the presence of organic solutes acting as promoters and inhibitors of radical chain reactions. Environmental Science \& Technology. 1985; 19(12):1206-1213. http://dx.doi.org/10.1021/ es00142a012. PMid:22280139.

2. von Gunten U. Ozonation of drinking water: part I. Oxidation kinetics and product formation. Water Research. 2003; 37(7):14431467. http://dx.doi.org/10.1016/S0043-1354(02)00457-8. PMid:12600374.

3. Valsania MC, Fasano F, Richardson SD and Vincenti M. Investigation of the degradation of cresols in the treatments with ozone. Water Research. 2012; 46(8):2795-2804. http:// dx.doi.org/10.1016/j.watres.2012.02.040. PMid:22417742.

4. Katsoyiannis IA, Canonica S and von Gunten U. Efficiency and energy requirements for the transformation of organic micropollutants by ozone, $\mathrm{O} 3 / \mathrm{H} 2 \mathrm{O} 2$ and $\mathrm{UV} / \mathrm{H} 2 \mathrm{O} 2$. Water Research. 2011; 45(13):3811-3822. http://dx.doi.org/10.1016/j. watres.2011.04.038. PMid:21645916.

5. Ciardelli G, Capannelli G and Bottino A. Ozone treatment of textile wastewaters for reuse. Water Science and Technology. 2001; 44(5):61-67. PMid:11695484.

6. Oliveira ARM and Wosch CL. Ozonólise: a busca por um mecanismo. Quimica Nova. 2012; 35(7):1482-1485. http:// dx.doi.org/10.1590/S0100-40422012000700034.

7. Rugg SJ. Ozone crack depth analysis for rubber. Analytical Chemistry. 1952; 24(5):818-821. http://dx.doi.org/10.1021/ ac60065a015.

8. Razumovsky SD, Podmasteriyev VV and Zaikov G. Kinetics of the growth of cracks of polyisoprene vulcanizates in ozone. Polymer Degradation \& Stability. 1986; 16(4):317-324. http:// dx.doi.org/10.1016/0141-3910(86)90088-1.

9. Lewis PM. Effect of ozone on rubbers: counter measures and unsolved problems. Polymer Degradation \& Stability. 1986; 15(1):33-66. http://dx.doi.org/10.1016/0141-3910(86)90004-2.

10. Criegee R. Mechanism of ozonolysis. Angewandte Chemie International Edition in English. 1975; 14(11):745-752. http:// dx.doi.org/10.1002/anie.197507451.

11. Miwa S, Kikuchi T, Ohtake Y and Tanaka K. Surface degradation of poly(ethylene-co-propylene-co-5-ethylidene-2-norbornene)

\section{Conclusions}

In order to select adequate polymer material for membrane contactor to be used in ozonation process in water treatment, it was investigated the resistance to ozone oxidation of different commercial polymeric membranes. Among the tested materials it was observed high resistance to ozone attack of polymers with electrophilic atoms attached to the carbon in the polymer backbone, like PVDF and PTFE. Polymers with single C-C or Si-C bonds, like PP and PDMS showed a certain resistance to ozone oxidation, but it was observed structural modifications with extended contact time. Polymers with carbon-carbon double bonds, like PEI and PES, were easily degraded by ozonation.

\section{Acknowledgements}

The authors acknowledge CNPq (Brazilian Council for Scientific Development) for scholarship of Felipe Santos.

terpolymer by ozone in water. Polymer Degradation \& Stability. 2011; 96(8):1503-1507. http://dx.doi.org/10.1016/j. polymdegradstab.2011.05.001.

12. Cataldo F. The action of ozone on polymers having unconjugated and cross- or linearly conjugated unsaturation: chemistry and technological aspects. Polymer Degradation \& Stability. 2001; 73(3):511-520. http://dx.doi.org/10.1016/S0141-3910(01)00140-9.

13. Oueslati R and Roudesli S. Etude par RPE de la decomposition thermique des peroxydes dans la fibre de polypropylene ozonise em Vue d'un Greffage. European Polymer Journal. 1991; 27(12):1383-1390. http://dx.doi.org/10.1016/0014 3057(91)90239-K.

14. Oueslati R and Catoire B. Ozonization et modifications morphologiques et physicochimiques de fibres de polypropylene. European Polymer Journal. 1991; 27(3):331-340. http://dx.doi. org/10.1016/0014-3057(91)90114-4.

15. Pezelj E and Cunko R. Influence of ozone as an air pollutant on polypropylene fiber properties. Textile Research Journal. 2000; 70(6):537-541. http://dx.doi.org/10.1177/004051750007000611.

16. Goto Y, Kitano K, Maruoka T, Yamamoto M, Kono A, Horibe $\mathrm{H}$, et al. Removal of polymers with various chemical structures using wet ozone. Journal of Photopolymer Science and Technology. 2010; 23(3):417-420. http://dx.doi.org/10.2494/ photopolymer.23.417.

17. Ouyang M, Yuan C, Muisener RJ, Boulares A and Koberstein JT. Conversion of some siloxane polymers to silicon oxide by UV/ozone photochemical processes. Chemistry of Materials. 2000; 12(6):1591-1596. http://dx.doi.org/10.1021/cm990770d.

18. Romero-Sánchez MD, Pastor-Blas MM, Martín-Martínez JM and Walzak MJ. Addition of ozone in UV radiation treatment of a synthetic styrene-butadiene-styrene (SBS) rubber. International Journal of Adhesion and Adhesives. 2005; 25(4):358-370. http:// dx.doi.org/10.1016/j.ijadhadh.2004.12.001.

19. Khulbe KC, Feng $\mathrm{C}$ and Matsuura T. The art of surface modification of synthetic polymeric membranes. Journal of Applied Polymer Science. 2010; 115(2):855-895. http://dx.doi. org/10.1002/app.31108.

20. MacManus LF, Walzak MJ and Mcintyre NS. Study of ultraviolet light and ozone surface modification of polypropylene. Journal of Polymer Science. Part A, Polymer Chemistry. 1999; 
37(14):2489-2501. http://dx.doi.org/10.1002/(SICI)10990518(19990715)37:14<2489::AID-POLA23>3.0.CO;2-G.

21. Sham ML, Li J, Ma P and Kim J. Cleaning and functionalization of polymer surfaces and nanoscale carbon fillers by UV/ozone treatment: A review. Journal of Composite Materials. 2009; 43(14):1537-1564. http://dx.doi.org/10.1177/0021998308337740.

22. Pabby AK and Sastre AM. State-of-the-art review on hollow fibre contactor technology and membrane-based extraction processes. Journal of Membrane Science. 2013; 430:263-303. http://dx.doi.org/10.1016/j.memsci.2012.11.060.

23. Sirkar KK. Membranes, phase interfaces, and separations: novel techniques and membranes: an overview. Industrial \& Engineering Chemistry Research. 2008; 47(15):5250-5266. http://dx.doi.org/10.1021/ie8001952.

24. Leiknes T, Phattaranawik J, Boller M, von Gunten U and Pronk W. Ozone transfer and design concepts for NOM decolourization in tubular membrane contactor. Chemical Engineering Journal. 2005; 111(1):53-61. http://dx.doi.org/10.1016/j.cej.2005.05.007.

25. Atchariyawut S, Phattaranawik J, Leiknes T and Jiraratananon R. Application of ozonation membrane contacting system for dye wastewater treatment. Separation and Purification Technology. 2009; 66(1):153-158. http://dx.doi.org/10.1016/j. seppur.2008.11.011.

26. Afrane $\mathrm{G}$ and Chimowitz EH. Experimental investigation of a new supercritical fluid inorganic membrane separation process.
Journal of Membrane Science. 1996; 116(2):293-299. http:// dx.doi.org/10.1016/0376-7388(96)00049-X.

27. Chiu YW and Tan CS. Regeneration of supercritical carbon dioxide by membrane at near critical conditions. The Journal of Supercritical Fluids. 2001; 21(1):81-89. http://dx.doi. org/10.1016/S0896-8446(01)00074-2.

28. Estay H, Bocquet S, Romero J, Sanchez J, Rios GM and Valenzuela F. Modeling and simulation of mass transfer in nearcritical extraction using a hollow fiber membrane contactor. Chemical Engineering Science. 2007; 62(21):5794-5808. http:// dx.doi.org/10.1016/j.ces.2007.05.037.

29. Sarrade S, Guizard C and Rios GM. Membrane technology and supercritical fluids: chemical engineering for coupled processes. Desalination. 2002; 144(1-3):137-142. http://dx.doi. org/10.1016/S0011-9164(02)00302-8.

30. Mark JE. Physical properties of polymers handbook. 2nd ed. Springer Science; 2007. http://dx.doi.org/10.1007/978-0-38769002-5.

31. Kumar A and Gupta RK. Fundamentals of polymer engineering. 2nd ed. New York: Marcel Dekker; 2003.

32. Silverstein RM, Webster FX and Kiemle DJ. Infrared spectrometry. In: Brennam D. Spectrometric identification of organic compounds. 7th ed. USA: John Wiley \& Sons; 2005. p. 85-152. 